\title{
Produção offshore na Bacia de Campos (RJ): a perspectiva da Psicologia do Trabalho
}

\section{Offshore production at the Bacia de Campos (Rio de Janeiro): a Work Psychology perspective}

\author{
Alexandre de Carvalho Castro'
}

\begin{abstract}
Resumo: O objetivo deste artigo é examinar a dinâmica psicológica dos trabalhadores offshore da Bacia de Campos (RJ). A técnica de grupo focal, enquanto metodologia de base qualitativa, foi utilizada para explorar opiniões, percepções, conceitos, atitudes e valores dos petroleiros. Seis grupos focais consistiram no procedimento metodológico por meio do qual foram colhidas informações sobre as condições de trabalho embarcado. Resultados: A análise do processo de trabalho em plataformas marítimas, com sua variabilidade e dificuldade, segundo a perspectiva da Psicologia do Trabalho, evidenciou que o tempo de trabalho, a vida e os ganhos dos trabalhadores são ambíguos, assimétricos e dissociados.
\end{abstract}

Palavras-chave: Psicologia do Trabalho. Grupo focal. Plataformas offshore. Fatores humanos. Organização do trabalho.

\begin{abstract}
The aim of this article is to examine the psychological dynamics among the offshore workers at the Bacia de Campos (Northern region of the state of Rio de Janeiro). The focus group, a qualitative research method, was used to explore the opinions, perceptions, concerns, behavior, and values of these offshore workers. Six focus groups were formed to gather information about their working conditions. Results: The analysis of the work process in offshore oil platforms, considering its variability and difficulties, from the perspective of work psychology, showed that the working hours, wages, and life of workers are very ambiguous, asymmetric, and dissociated.
\end{abstract}

Keywords: Work Psychology. Focus groups. Offshore oil platforms. Human factors. Work organization.

\section{Introdução}

Este artigo decorre de uma pesquisa concebida no âmbito da Psicologia do Trabalho e desenvolvida com bolsas de iniciação científica mantidas pelo CNPq e pela Coordenadoria de Pesquisa e Estudos Tecnológicos do Centro Federal de Educação Tecnológica Celso Suckow da Fonseca (RJ). Além disso, em função de alguns resultados parciais, constituiu-se a partir de trabalhos anteriores apresentados em eventos e congressos nacionais de Engenharia de Produção (XIV SIMPEP, XVIII ENEGEP, IV CNEG, XXIX ENEGEP). Esses estudos aludiram tanto a processos psicológicos das relações de saúde/doença no âmbito da organização do trabalho realizado em plataformas marítimas (CASTRO et al., 2007; CASTRO; VINAGRE, 2009) quanto a processos por meio dos quais empresas petrolíferas classificam dados sobre as condições de estresse (CASTRO; NUNES, 2008a), e os gerenciam (CASTRO; NUNES, 2008b; CASTRO, 2012).

Este texto, contudo, não consiste em mera reprodução daquilo que foi apresentado nos congressos.
Ao contrário, inclui novos dados, sistematiza os desdobramentos dessas e de outras pesquisas dentro do mesmo tema, incorpora conclusões da produção bibliográfica mais recente e aprofunda as questões suscitadas desde então, principalmente em relação ao tempo, à vida e aos ganhos no trabalho embarcado. Até porque a efervecência neste campo de investigações acompanha o crescente desenvolvimento econômico e tecnológico verificado no contexto da produção offshore (localizada ou executada em plataformas marítimas).

Realmente, é possível verificar, numa análise da produção brasileira de petróleo dos últimos anos, um grande desenvolvimento do trabalho offshore, particularmente na Bacia de Campos (BRUNI, 2002; FURTADO; FREITAS, 2004). E isso sem falar das perspectivas futuras de maior desenvolvimento ainda, quando forem efetivadas as atividades no megacampo de Tupi, na Bacia de Santos, onde a reserva é estimada numa faixa entre 5 bilhões e 8 bilhões de barris de petróleo. Segundo a perspectiva

\footnotetext{
${ }^{1}$ Programa de Pós-graduação em Tecnologia - PPTEC, Centro Federal de Educação Tecnológica Celso Suckow da Fonseca - CEFET/RJ, Av. Maracanã, 229, Bloco E, $5^{\circ}$ andar, CEP 20271-110, Rio de Janeiro, RJ, Brasil, e-mail: o.aken@uol.com.br
} 
dos avanços tecnológicos, o quadro é impressionante, pois a Petrobras tem obtido seguidos recordes em atividades de perfuração em águas cada vez mais profundas.

No início dos anos 70, por exemplo, a capacidade de operação em lâminas d'água (termo técnico que indica a distância entre o solo marinho e o nível d'água) era mínima, pois as primeiras instalações de produção offshore consistiam em plataformas fixas de pequeno porte (o primeiro reservatório marítimo descoberto no Brasil estava localizado no litoral do Nordeste sob lâmina d'água de 30 metros). A partir de 1971, entretanto, com o início da perfuração exploratória na Bacia de Campos, surgiu uma nova tendência, que efetivamente se consolidou em dezembro de 1974, com a descoberta de petróleo no campo de Garoupa (sob lâmina d'água de 120 metros). Assim, em virtude do potencial energético da Bacia de Campos (FREITAS, 1995), esse episódio desencadeou um processo de transformação na indústria nacional, levando a Petrobras, por meio de seu Centro de Pesquisas (Cenpes), a desenvolver tecnologia para produção de petróleo em águas profundas (mais de 400 metros de lâmina d'água) e ultraprofundas (mais de 1000 metros).

Em que pese o fato de que essa análise histórica será aprofundada oportunamente, para o escopo desta introdução, essa referência geral contribui especificamente para salientar dois importantes aspectos. O primeiro deles é o interesse do tema para a Engenharia de Produção, já que a capacidade operativa decorrente de novas tecnologias viabilizou e incrementou a produção de petróleo em plataformas marítimas baseadas em profundidades cada vez maiores. E o segundo ponto é que esse processo produtivo também interessa sobremaneira à Psicologia do Trabalho, porque tais avanços acarretaram nítidos impactos psicológicos na subjetividade do trabalhador offshore. Ou seja, há de se ressaltar uma tensão implícita nessa conjuntura, porque se por um lado são dignas de crédito as conquistas tecnológicas, por outro precisam ser avaliados os seus perversos efeitos marcados por desgaste mental e emocional no trabalho.

Pesquisas realizadas com o enfoque da Psicologia do Trabalho mostram que a prospecção de petróleo em águas profundas geralmente implica uma significativa perda da qualidade de vida (CASTRO; PINTO; IGNÁCIO, 2005; CASTRO; IGNÁCIO; PINTO, 2006). O que se verifica é que as condições de trabalho embarcado produzem efeitos ligados à falta de satisfação e realização humana, afetando dessa forma a saúde física e mental do trabalhador (SAMPAIO, 2001).

A relevância deste estudo, então, se estabelece em função do panorama atual do País diante dos desafios das fontes de energia, uma vez que é possível constatar - no caso do trabalho offshore - que na medida em que a tecnologia de prospecção se desenvolve, viabilizando a construção de novas plataformas e o aumento da oferta de empregos no setor, as implicações para o psiquismo do trabalhador, paradoxalmente, muitas vezes pioram. Assim, tendo em vista tal realidade, esta investigação teve como objetivo analisar a dinâmica psicológica dos trabalhadores offshore nos processos de produção em curso nas plataformas da Bacia de Campos.

\section{Metodologia}

A metodologia aqui adotada foi a de "Grupos Focais" (KRUEGER, 1994), técnica de investigação que viabiliza o levantamento de percepções e impressões dentro de um determinado grupo social. A partir de um foco de discussão em grupo (por isso, Grupo Focal), são estabelecidos pontos de concordância, ou discordância, que, uma vez interpretados, vão representar os pontos de vista presentes nas reuniões e encontros realizados.

A coleta qualitativa dos dados de pesquisa no Grupo Focal, portanto, tem como premissa o fato de que as pessoas tendem a elaborar opiniões mediante processos de interação social. Perspectiva que mantém um forte contraste com métodos em que grupos são interpretados com base em dados colhidos individualmente. Ou seja, um Grupo Focal é mais do que a soma quantitativa dos indivíduos que dele participam, porque a interação no grupo permite o desvelamento de situações latentes que muitas vezes não se manifestariam sem o confronto intergrupal. Segundo Carlini-Cotrim (1996, p. 287):
As pessoas, em geral, precisam ouvir as opiniões dos outros antes de formar as suas próprias, e constantemente mudam de posição (ou fundamentam melhor sua posição inicial) quando expostas à discussão em grupo.

De fato, o Grupo Focal é constituído segundo um procedimento muito distinto das Entrevistas Grupais. Nesse sentido, é preciso ficar claro desde já que caracterizações individuais acerca dos participantes de cada grupo não são efetivamente relevantes para a análise aqui delineada (pressuposto que deve pautar a análise das figuras e tabelas, em prol do foco no que é significativo e importante). Essa questão acerca da descrição dos grupos, aliás, é amplamente debatida na bibliografia sobre o tema, principalmente porque alguns confundem Grupo Focal e Entrevistas Grupais. Ora, o que é necessário ter em mente é que as Entrevistas Grupais estão de fato preocupadas com características individuais, sobretudo porque entrevistadores de grupo pretendem ouvir a opinião de cada participante e comparar suas respostas, configurando um nível de análise que se orienta em direção ao indivíduo no grupo. Os Grupos 
Focais divergem dessa perspectiva individualizante porque tal método de pesquisa visa prioritariamente estudar as interações grupais. Em outras palavras, o propósito de análise do grupo focal é o próprio grupo (GONDIM, 2002).

Dessa forma, como o que importa no método adotado neste estudo é a característica do grupo em si, e não as características distintivas das pessoas dentro do grupo, há de se ressaltar que a seleção dos participantes derivou fundamentalmente do grupo social implicado no objetivo da pesquisa: os trabalhadores embarcados em plataformas marítimas. Assim, os grupos focais foram compostos de quatro a oito pessoas, sendo seu tamanho condicionado por alguns importantes fatores. A ideia é que o grupo fosse pequeno o suficiente para que cada pessoa tivesse a oportunidade de compartilhar suas ideias e percepções. Por outro lado, precisava ser grande o bastante para possibilitar a diversidade de opiniões (mas não muito grande a ponto de trazer problemas por uma tendência a se fragmentar).

Logo, foram formados seis grupos - um em Campos dos Goytacazes, um em Macaé e quatro na cidade do Rio de Janeiro - compostos por um total de 34 petroleiros vinculados à Petrobras, que foram selecionadas em função de trabalharem em plataformas offshore na Bacia de Campos. Esses participantes foram entrevistados fora do ambiente de trabalho, nos seus dias de folga, em reuniões com duração aproximada de uma hora e trinta minutos, no período de tempo compreendido entre outubro de 2006 e março de 2010 (vide Tabela 1 e Figura 1).

Essa metodologia visava manter contato direto com trabalhadores de distintas unidades de perfuração marítima, nas ocasiões em que não estavam embarcados. A ideia era que múltiplos grupos homogêneos - com participantes similares - necessários para se detectar padrões e tendências por meio dos grupos.

Cada reunião contou com um moderador (estudante/bolsista de iniciação científica) cuja função era promover o debate em torno de um roteiro previamente estipulado. Tal procedimento evitou que particularidades de cada grupo (um participante extremamente dominante, por exemplo) inviabilizassem a percepção de questões relevantes, inclusive porque o propósito não era chegar a um consenso ou uma tomada de decisão.
Os tópicos de discussão no grupo focal foram cuidadosamente determinados, organizados e sequenciados na estrutura do roteiro. Essa organização se baseou em uma análise em profundidade do tema em foco, a partir das contribuições dos outros estudos (RODRIGUES, 2001; FREITAS; SOUZA; MACHADO, 2001; VIDEIRA, 2001; SAMPAIO, 2001; PENA, 2002). Assim, as questões foram colocadas em um contexto compreensível e lógico para os participantes do grupo e tinham como objetivo perscrutar a produção offshore em suas implicações quanto à dinâmica do trabalho realizado.

Nos debates de cada um dos grupos constituídos, os processos de investigação giravam em torno dessas perguntas voltadas a criar um ambiente aberto às diversas opiniões. Como dispositivo de pesquisa, seu principal ponto forte dizia respeito à facilidade de oferecer condições para que os participantes trocassem ideias livremente, criando uma dinâmica em que os membros do grupo se influenciavam mutuamente. Por isso, consistiu numa discussão que pretendia ampliar o entendimento acerca da maneira como a organização psicossocial do trabalho embarcado afetava o trabalhador que desenvolve sua prática laboral nas plataformas. $\mathrm{O}$ que equivale também a dizer que as questões levantadas na entrevista giravam em torno de quais seriam, então, as relações entre a maneira como o trabalho é organizado numa plataforma de petróleo e a saúde mental do trabalhador.

As reuniões de cada grupo foram gravadas e posteriormente transcritas. A partir daí, foram elaborados seis relatórios, um de cada grupo, que, após processo de sistematização - no qual se procurou agrupar depoimentos convergentes sob os mesmos cabeçalhos a fim de formarem temas específicos -, foram cotejados e indexados.

Em todo esse processo, no entanto, o método usado jamais constituiu um fim em si mesmo, pois visava coletar dados que somente teriam sentido em função de uma determinada base epistemológica, ou seja, o referencial teórico empregado na interpretação. Obviamente, a análise dos dados coletados demandou uma perspectiva teórica compatível à metodologia, pois - principalmente em se tratando de uma perspectiva qualitativa - a base teórica e o método não poderiam de modo algum ser discrepantes.

Tabela 1. Caracterização dos Grupos Focais.

\begin{tabular}{cccc}
\hline Número de Grupos & Local & Participantes & Número de Sessões \\
\hline Grupo 1 & Macaé & 5 & 1 \\
Grupo 2 & Rio de Janeiro & 6 & 1 \\
Grupo 3 & Campos & 4 & 1 \\
Grupo 4 & Rio de Janeiro & 8 & 1 \\
Grupo 5 & Rio de Janeiro & 6 & 1 \\
Grupo 6 & Rio de Janeiro & 5 & 1 \\
\hline
\end{tabular}




\section{Perfil dos participantes dos Grupos Focais:}
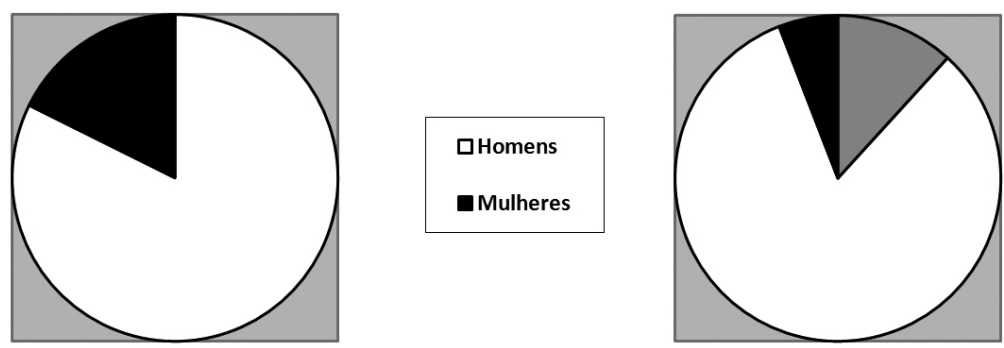

$\square$ idade inferior a 25

口Homens

Mulheres

$\square$ entre 25 e 35 anos

acima de $\mathbf{3 5}$ anos
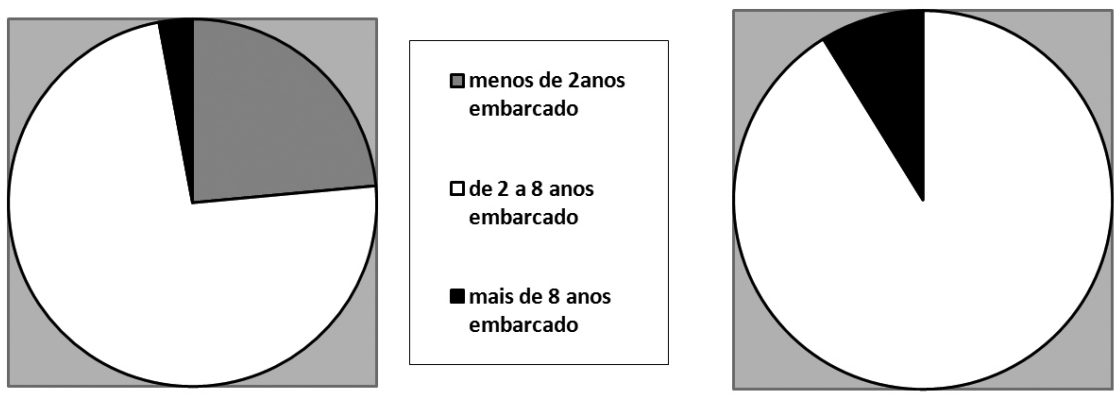

पTécnicos de níve

médio

$\square$ de 2 a 8 anos embarcado

mais de 8 anos embarcado
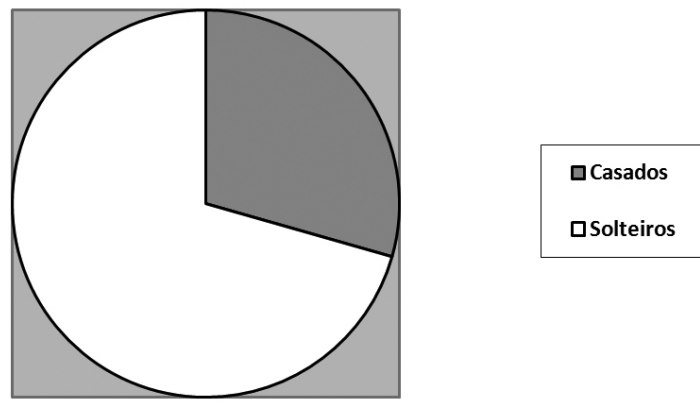

Figura 1. Caracterização dos participantes dos Grupos Focais.

Do ponto de vista metodológico, a opção por Grupos Focais encontra-se fundamentada na tradição do trabalho com grupos, na sociologia e na psicologia social crítica, haja vista suas contribuições sobre análises discursivas e produção de sentido (KIND, 2004). Então, por conta da coerência em relação aos pressupostos que sustentaram esta investigação, a análise e interpretação dos relatórios oriundos dos grupos foram realizadas a partir da teoria de Mikhail Bakhtin (2004), particularmente marcada pela valorização da interação verbal, tendência igualmente encontrada em outros estudos que usam o mesmo método (ver, por exemplo, TEIXEIRA, 2009).

Consequentemente, o processo de análise - ainda que sistemático - não implicou tratamento estatístico, mas um procedimento indutivo em que categorias idiográficas e hipóteses explicativas derivaram basicamente das opiniões recorrentes nos grupos pesquisados. Pois, como se sabe, tanto os Grupos
Focais aludem à construção de conhecimento em espaços de intersubjetividade, quanto a teoria bakhtiniana sublinha que os sentidos discursivos somente ganham contorno significativo na interação social. Para Bakhtin (2004), as condições de produção de um discurso não podem ser entendidas exclusivamente como circunstâncias pessoais de um ato de enunciação, mas como uma complexa instância da qual emergem conflitantes posições políticas e sociais (CASTRO; PORTUGAL; JACO-VILELA, 2011). Perspectiva, portanto, bastante indicada para análise das diversas falas dos trabalhadores.

\section{Características do trabalho offshore}

As atividades de exploração, perfuração, produção e transferência de petróleo do mar são regidas pela lei 5.811/72 (BRASIL, 1972). Por esse motivo, o trabalho em plataformas marítimas possui características bem específicas no que diz respeito à remuneração, 
aos períodos de trabalho e aos de descanso. Os salários de petroleiros embarcados são superiores aos de trabalhadores não embarcados (MOITAS, 2011), fato que é recorrentemente aludido pela grande mídia, em reportagens em que as vantagens oferecidas pelo trabalho offshore apontam claro apelo econômico (SCHELLER, 2012). O percentual específico de comparação entre salários varia de tempos em tempos, mas, segundo dados divulgados em março de 2013, a remuneração desses trabalhadores offshore correspondia a valores $58 \%$ acima da média nacional (THIELMANN, 2013).

Quanto ao dia a dia e a rotina de atividades, pode-se dizer que há muitas semelhanças entre as plataformas. Na maioria das vezes, os trabalhadores atuam em turnos de 12 horas (com escala de trabalho das $7 \mathrm{~h}$ às $19 \mathrm{~h}$ e das $19 \mathrm{~h}$ às $7 \mathrm{~h}$ ), mas há exceções, pois há o regime referido como de "sobreaviso", a fim de garantir a normalidade das operações, ou para atender aos imperativos de segurança industrial. Nessas circunstâncias, é exigida a disponibilidade do trabalhador em tempo integral (no local de trabalho ou nas suas proximidades), por 24 horas, mesmo durante o período que seria destinado ao repouso e descanso. Os petroleiros embarcados que não estão de sobreaviso, entretanto, usufruem, nas horas vagas, espaços de lazer na própria plataforma: piscina, futebol, academia, cinema e churrasqueira. Convém também ressaltar que, por conta da legislação específica, os trabalhadores offshore têm direito à folga de 14 dias para cada 14 dias de trabalho. Para os concursados da Petrobrás, no entanto, o direito é ampliado, e eles podem dispor de 21 dias de descanso para 14 dias embarcados.

O conjunto dessas características, consequentemente, põe em relevo uma constatação importante. As plataformas marítimas de produção ou prospecção de petróleo constituem sistemas complexos no que diz respeito ao gerenciamento dos riscos, porque estão basicamente ligadas ao processamento de hidrocarbonetos inflamáveis, ao uso de compostos químicos tóxicos, e à operação de equipamentos que podem desencadear acidentes de grandes proporções (FREITAS; SOUZA; MACHADO, 2001). Logo, além de se aludir às condições de trabalho dentro de uma plataforma, é fundamental entender como a atividade offshore foi se constituindo, ao longo dos anos, no cenário brasileiro.

Do ponto de vista histórico, apesar de terem ocorrido algumas iniciativas incipientes antes dos anos 1950, a prospecção de petróleo no Brasil começou a se desenvolver de fato com a criação da Petrobras, em 1954 (VIDEIRA, 2001). Depois de um período inicial que se caracterizou pela concentração de esforços na região do Recôncavo Baiano e na Amazônia, com a descoberta do campo de petróleo de Guaricema na plataforma continental de Sergipe/Alagoas, em 1968, surgiram novas perspectivas, por meio da prospecção offshore. No entanto, uma vez que a importação do petróleo era muito barata, até 1972, o investimento da Petrobras em pesquisa era majoritariamente voltado para a área do refino (ORTIZ NETO; SHIMA, 2008).

Contudo, o impacto da crise do petróleo em 1973, associado à descoberta do campo de Ubarana na porção marítima da Bacia Potiguar (ES), levaram a uma elevação de investimentos no mar que culminou, no final de 1974, na primeira descoberta importante: o campo de Garoupa na Bacia de Campos (LUCCHESI, 1998).

Conforme já foi indicado na introdução, a descoberta do campo de Garoupa marcou um divisor de águas na exploração do petróleo no Brasil, pois a confirmação do potencial petrolífero dessa região implicou a decisão de avançar a exploração para águas profundas. Assim, em 1984, foram descobertos, ainda na Bacia de Campos, o campo de Marimbá e o de Albacora, fato que indicou como irreversível a opção pela prospecção offshore. O avanço para águas ultraprofundas, por sua vez, ocasionou novas descobertas: os campos de Barracuda e Roncador (MILANI et al., 2000).

A dimensão econômica e social desse fenômeno, nesse período, pode ser avaliada a partir de indicadores importantes. Pois a produção offshore da Petrobras aumentou de $1,7 \%$, em 1987, para mais de $55 \%$, em 2000, ano em que ela ganhou o prêmio de melhor empresa de produção offshore na Offshore Technology Conference (OTC), em Houston, nos Estados Unidos (BRUNI, 2002; FURTADO; FREITAS, 2004). Vale lembrar, todavia, que com a reestruturação de mercado em 1997, a criação da Agência Nacional de Petróleo (ANP), e a consequente abertura do mercado às multinacionais, a exploração offshore na Bacia de Campos passou a ser do interesse não só da Petrobras, mas também de muitas firmas estrangeiras (ORTIZ NETO; COSTA, 2007).

Dessa forma, por conta da necessidade de extrair petróleo das reservas marítimas, houve amplo incremento das atividades offshore, mormente no Estado do Rio de Janeiro. Pois, paralelamente ao desenvolvimento de novas tecnologias a fim de explorar e produzir petróleo no meio do mar, de forma rentável, emergiu também uma nova categoria de profissionais para trabalhar nessas instalações (CARNEIRO, 2006). Profissionais esses que, por sua vez, tanto incorporaram funções oriundas da indústria onshore, quanto algumas outras características, derivadas ou da marinha ou do próprio ambiente específico de trabalho offshore.

Os estudos realizados com tais trabalhadores no âmbito da Psicologia do Trabalho, entretanto, têm constatado que vários problemas acompanharam o desenvolvimento de atividades em plataformas marítimas (PENA, 2002), evidência que inclusive 
levou pesquisadores voltados para metodologias quantitativas e psicométricas a desenvolverem uma escala de avaliação de estressores ambientais offshore, em amostras brasileiras (SILVA JÚNIOR; FERREIRA, 2007).

Realmente, apesar de essa atividade ter apenas cerca de três décadas, a Bacia de Campos tem acumulado um histórico considerável de acidentes graves, inclusive com o surgimento de diversos quadros de adoecimento psíquico, como consequência da exposição dos trabalhadores a uma situação em que o trabalho é concomitantemente intenso, coletivo e complexo.

O trabalhador envolvido na exploração do petróleo na Bacia de Campos tem um trabalho intenso porque a produção deve fluir ininterruptamente, durante as 24 horas de todos os dias ao longo do ano, condição, aliás, que demanda o revezamento de vários grupos de trabalhadores na execução das tarefas (contingência que, convém mencionar, não é restrita ao labor offshore). Além disso, uma vez que as diversas partes desse sistema tecnológico se encontram interligadas numa estrutura de rede, em que há inúmeras conexões e os componentes estão complexamente acoplados, os casos de falhas podem acarretar acidentes graves devido à imprevisibilidade das múltiplas interações que venham a se estabelecer (ALVAREZ et al., 2007). Daí a classificação das atividades offshore como interdependentes, desgastantes e perigosas. Afinal de contas, estão sempre sujeitas a certo grau de desencadeamento de efeitos do tipo dominó em caso de incidentes e acidentes (FREITAS; SOUZA; MACHADO, 2001).

Por outro lado, a ampliação do volume de operações e de instalações, a fim de atender a crescente demanda mundial por combustível, concorre para que muitas plataformas de petróleo marítimas operem nos limites de sua capacidade instalada. O que traz, como consequência para o trabalhador, a ampliação e agravamento dos riscos à saúde física e mental (PENA, 2002).

Os trabalhadores de plataformas de petróleo marítimas frequentemente enfrentam um ambiente hostil de trabalho, pois permanecem confinados durante, aproximadamente, duas semanas. Por ocasião da CPI instaurada pela ALERJ sobre a falta de segurança e condições de trabalho nas plataformas petrolíferas do Estado do Rio de Janeiro, o Sindicato dos Petroleiros do Norte Fluminense elaborou um dossiê, em junho de 1997, em que denunciou a elevada incidência dos seguintes transtornos mentais nos trabalhadores: disfunções fisiológicas originadas em fatores mentais; reação aguda ao estresse; transtornos específicos do sono; problemas de relacionamento; estados fóbicos e de ansiedade (SINDICATO..., 1997). Esse documento destaca-se como fundamental para análise, tanto das diversas irregularidades que corroboraram para a degradação de condições de trabalho offshore, quanto dos acidentes ocorridos, por ser um levantamento feito por autoridades externas à Petrobras (CARNEIRO, 2006).

No que diz respeito especificamente à dinâmica do sofrimento psíquico, esse dossiê listou uma série de circunstâncias vinculadas aos transtornos mentais, em que se destacaram: o afastamento do convívio sociofamiliar; os sentimentos de não participação nos momentos importantes do grupo familiar; e a exposição prolongada a situações de risco. Tais fatores permitiram até a indicação de que o sintoma social que mais se expressava correlacionado ao isolamento era o alcoolismo, porque o álcool (a exemplo das demais drogas) permitia uma elevação ilusória do nível de suporte à frustração (SINDICATO..., 1997).

Nesse campo de estudos, muitas outras investigações têm sido realizadas. Há pesquisas sobre a produção offshore que constatam evidências subjetivas e objetivas de relação entre sofrimento psíquico e condição de trabalho (SAMPAIO, 2001), aspecto igualmente ressaltado por estudos que mostram os trabalhadores terceirizados como sendo os principais atingidos (ALVAREZ et al., 2007) - quando comparados com os trabalhadores diretos das empresas - uma vez que os riscos se agravam e se ampliam pelo fato de receberem não somente menos treinamento e informação, mas também por trabalharem em condições mais precárias (FREITAS; SOUZA; MACHADO, 2001).

Entre os fatores que podem influenciar a condição psíquica dos trabalhadores offshore, são frequentemente listados: o confinamento como limitação de espaço e como repressão ao desejo de ir e vir; isolamento social; distância da família em eventos de grande significado simbólico; ausência de privacidade à bordo; e abstinência sexual forçada (RODRIGUES, 2001).

Ademais, a assimetria funcional entre as categorias de "petroleiros" e "contratados", em plataformas da Petrobras, é apontada como problemática, porque a eventual mútua discriminação pode contribuir para o agravamento dos problemas já enfrentados pelos trabalhadores offshore em plataformas petrolíferas, nas quais o constante risco de acidentes fatais deveria demandar confiança e solidariedade entre todos, para garantia da própria sobrevivência (PENA, 2002).

\section{Os resultados da pesquisa com os grupos focais}

Em relação aos resultados desta pesquisa, há de se destacar mais uma vez que a análise não se pautou em amostras probabilísticas e nem objetivou indicar quantitativamente quaisquer opiniões individuais, ainda que dentro de sessões de grupo. Ao contrário, os grupos focais foram particularmente úteis para providenciar informações acerca dos mecanismos como os trabalhadores offshore pensam, ou por que 
se sentem de uma maneira determinada. Desse modo, os resultados aqui apresentados se inserem nessa tentativa de ampliar o crescente campo de estudo voltado para a análise psicossocial do trabalho em plataformas na Bacia de Campos.

De acordo com Bakhtin (2004), o fluxo da interação social conduz a um movimento de circulação do discurso em que o sentido das palavras, noções e conceitos se reconstituem continuamente. $\mathrm{O}$ enunciado dirigido a um dado interlocutor dirige-se, na verdade, às maneiras pelas quais os sentidos múltiplos daquela temática circulam, tanto da consciência de quem fala, quanto na de quem ouve. Em suma, discursos variados modulam mutuamente a amplitude histórico-social de construção do sentido, por meio de processos que estabelecem respostas para as questões levantadas anteriormente por outras vozes, em outros lugares.

Desse modo, conforme enfatizado quando da apresentação da metodologia, foram usadas na discussão algumas questões abertas cuidadosamente desenvolvidas para gerar uma reflexão dentro do grupo. As primeiras perguntas - "Como é um dia de trabalho na plataforma?"; "O que vocês acham desse tipo de trabalho offshore?"; "Em que sentido a vida de vocês mudou depois que foram trabalhar offshore?" - tinham por objetivo básico fazer uma exploração inicial do objeto de estudo.

Nesse momento inicial, as respostas dos trabalhadores tinham um efeito catalisador no debate, pois se um concordava - "eu também diria mais ou menos isso" - o outro, por exemplo, ponderava: - "não tem como".

$\mathrm{O}$ roteiro, enquanto instrumento da pesquisa, funcionou como um guia da entrevista. Sendo assim, a análise das respostas obtidas foi direcionada no sentido de compreender as ambivalentes dimensões psicológicas presentes nos processos produtivos das plataformas. Para o trabalhador, porém, o que eventualmente mais importava era a oportunidade de extravasar

- Como eu tô há pouco tempo na empresa, eu vou para o meu sexto embarque, não dá para atuar direito na área. Logo, a gente deixa para os mais experientes tomarem conta, mas eu fico na sala de controle tentando entender um pouco do processo e o serviço é estressante! Você está no meio de um monte de risco lá, e é uma tensão do caramba!

Conforme verificado no levantamento bibliográfico sobre estudos offshore, a problemática da família foi ressaltada em várias investigações (SINDICATO..., 1997; RODRIGUES, 2001; SAMPAIO, 2001). Por esse motivo, no roteiro foram incluídas perguntas - "Como ficam as relações familiares de quem trabalha offshore?" - que procuravam verificar o que os trabalhadores pesquisados consideravam acerca das questões apontadas como pertinentes por outros autores.

E essa temática familiar também emergiu de forma ambígua nos grupos focais, porque enquanto um indicava a ausência do problema

- Minha filha nasceu, pedi pra descer, desci tranquilo. De repente meu sogro faleceu, pedi pra descer, e você sabe que quando não é parente direto eles não liberam, mas desci [...]

outro discordava abertamente

O que eu vejo é que você ainda não passou certos problemas embarcado. Vou pedir a Deus que você nunca passe. Pois você está com problemas sérios, às vezes, de doença na família e tudo, e você às vezes chega lá e pede pra descer, e dizem: 'amanhã não tem voo, volta depois de amanhã'. Aí você vai sentir na carne o que a gente tá falando.

Essas diferentes opiniões dos trabalhadores, aliás, exemplificam o quanto os resultados foram obtidos em discussões sobre questões abertas, que proporcionaram um ambiente mais dialógico que o de uma entrevista individual. E, além disso, a principal vantagem nesta composição metodológica com os grupos focais foi perceber que as discussões puderam proporcionar maior compreensão acerca do sentido e interpretação de dados já ressaltados em outras pesquisas.

De acordo com os aspectos referidos anteriormente, os grupos focais envolveram trabalhadores em interações sociais em uma série de discussões acerca de vivências comuns entre eles. Assim, a interação efetivamente produziu dados qualitativos que possibilitaram insights em relação às atitudes, percepções e opiniões dos participantes. O que significa dizer que cuidadosas e sistemáticas análises das discussões implicam categorizações acerca de como as questões foram percebidas. Nessa perspectiva, as indicações das falas aqui representadas não terão a preocupação de identificar individualmente os participantes de cada grupo. Ao contrário, o procedimento que prevalecerá será o de citar cada declaração sem indicação de procedência individual, pois o que se procura é apontar padrões e tendências sociais.

Isso porque, segundo a ótica bakhtiniana, quando enunciados produzidos num domínio de atividade idêntica apresentam traços recorrentes, uma forma comum de pensar e falar deve ser entendida como um gênero de discurso. A ideia é que esse repertório de formas discursivas, uma vez relacionadas dentro de um grupo social homogêneo ainda que oriundas de diferentes sujeitos individuais, constitui um espelho coletivo que reflete o cotidiano enfrentado. Nos grupos estudados, tais formas discursivas - vide representação esquemática da Tabela 2 - refletiram, 
Tabela 2. Representação das formas discursivas.

Categorias recorrentes identificadas nos Grupos Focais

\begin{tabular}{ll} 
Depoimentos frequentes que versavam sobre... & (a) o tempo como assimétrico; \\
& (b) a vida como dissociada; \\
\hline
\end{tabular}

portanto, opiniões e conceitos sobre o tempo, a vida e a remuneração no trabalho embarcado, conforme detalhamento apresentado a seguir.

\subsection{A pesquisa indicou que os trabalhadores offshore tendem a perceber o tempo assimetricamente}

A problemática do tempo de trabalho foi frequentemente aludida nos vários grupos: - "O que eu vejo é que são doze horas que jogam nas suas costas e ninguém quer nem saber das suas condições físicas e psicológicas." O dado a ser ressaltado, todavia, é que essas tais doze horas, como o próprio trabalhador salientou, eram marcadas pela subjetividade, posto que não estavam nos ponteiros do relógio, mas "nas costas", carregadas como um peso, um fardo. Em outras palavras, o tempo offshore não é objetivo, ou mensurável: - "Uma coisa que eu sempre falei é que 14 dias lá [na plataforma] demoram muito mais pra passar do que 21 dias aqui [em terra], com certeza." Às vezes o tempo offshore transmuda-se até em um não tempo, um vazio atemporal: - "Fica um vácuo de 14 dias na sua vida. É meio estranho..."

Segundo a descrição feita pelos petroleiros, as horas do turno de trabalho diário não têm uma dimensão quantitativa (restrita a doze períodos de sessenta minutos), mas assumem um caráter subjetivo:

- A minha vida é literalmente de escravo. Tanto existem vezes que a gente trabalha 12 horas num dia, quanto existem vezes que a gente trabalha 80 horas num dia.

E a explicação para a assimetria das horas é dada em função das exigências da tarefa:

- É muito sinistro, literalmente falando, porque a gente lida diretamente com equipamentos de pressão, com dados em tempo real, com gente na nossa cola o tempo todo.

O petroleiro sabe que seu tempo de trabalho efetivo, seu descanso, a quantidade de trabalhos realizados e o tempo de duração de cada atividade são criteriosamente aferidos. Assim sendo, é interessante perceber em sua fala que, quando ele se refere ao "tempo real" indica, na mesma frase, outro tempo, percebido em termos bem coercitivos - "o tempo todo". E esse tipo de percepção é compartilhada coletivamente, conforme pode ser observado na concordância de outra pessoa dentro desse mesmo grupo: - "Claro. Time is money!"

Na Psicologia do Trabalho, autores que privilegiam abordagens quantitativas tomam como premissa a rigidez do controle técnico de tempos e ritmos do maquinário para indicar efeitos negativos e estressantes sobre os trabalhadores (GARDELL, 1991). Dentro de um viés bakhtiniano, contudo, os dados coletados nos Grupos Focais mostram um panorama mais grave, pois, no caso do trabalho embarcado, paradoxalmente, além do problema da rigidez, há também o da fluidez. E esse templo flexibilizado torna as condições ainda mais perversas, já que, às vezes, o tempo da tarefa sequer é estipulado, dada a imprevisibilidade inerente às atividades:

- Você pode ter algum problema em um poço e ficar horas e horas trabalhando além das doze que sempre pedem pra gente cumprir. [...] Mas é praticamente impossível ficar só doze horas em um poço. Se eu pudesse ficar doze horas num poço eu nunca precisaria de um psicólogo.

Tempus fugit, pois o tempo que marca as tarefas é veloz: - "Naquela rotina mais acelerada, o tempo acaba passando um pouco mais rápido." Contudo, assimetricamente também é percebido como um tempo que pode desacelerar:
- Você fica preocupadíssimo em manter a cabeça ocupada em alguma coisa pro tempo correr. Porque se você fica ocioso, o tempo demora à beça pra passar. Você fica olhando pro relógio desesperado.

Em certos casos, numa perspectiva mais existencial, não somente o relógio congela, mas a própria vida estaciona, para:
- Não gosto de estar lá, presa, embarcada. Porque a minha vida praticamente parou. Faculdade, tudo, eu tive que mudar já quinhentas vezes. Era pra eu me formar daqui a pouco, e eu ainda não saí de onde eu queria.

Assim, há a descrição de um tempo extremamente célere, mas concomitantemente estanque, fixo, parado. $\mathrm{O}$ que se verifica é que os trabalhadores se referem a um tempo concebido de forma paralela. É como se houvesse dois tempos diferentes, um que é percebido 
na plataforma marítima como penoso, e outro, mais dinâmico, que transcorre na vida cotidiana, em terra:

F: Pra mim não é legal ficar tanto tempo longe, e ver minha vida parar por 14 dias em terra. Porque a minha vida para, mas o mundo continua aí... E: Quando você volta tem que se adaptar ao novo mundo que você encontra. F: Exatamente. Esses 14 dias que você não viu.

O tempo de trabalho embarcado não só é percebido como um tempo perdido, mas também como um fator que inviabiliza as oportunidades do tempo de descanso:

Nunca vou poder arranjar um namorado [...] Você conhece uma pessoa, e fica 14 dias lá [na plataforma]. Ora, em 14 dias a pessoa já conheceu outra. Já abriu espaço pra outras, entendeu? Isso é muito ruim.

Mesmo dias específicos podem ter significados diferentes, em função de se estar offshore, ou não:

- Imagina o teu aniversário. Você tá mal de cabeça, não quer nem sair da tua cama. Aí você liga pra casa, porque a sua mãe fica triste se você não ligar, então falam assim: Vamos cantar todo mundo parabéns pra ela! Aí te dá uma sensação de... sozinha.

Dada a assimetria de tempos de trabalho e descanso, que se desenvolvem com velocidades distintas, o petroleiro tende a conceber o seu período embarcado como uma espécie de contagem regressiva:

F: Do dia que você chega até o dia que você vai embora, parece que você viveu aquele único dia. L: Sabe uma coisa que é verdade? Se você embarcou numa segunda, segunda não passa a ser segunda. Passa a ser o primeiro dia do seu embarque. B: É, o primeiro dia do embarque. L: Aí terça, não é terça. É o segundo dia. E aí vai, até o último. Isso é curioso. Todo mundo fala: Pô, tá há quanto tempo aí? E o outro responde: Quarto dia. Ou então: Que dia é hoje? É o quarto dia. Entendeu? F: É. Você não sabe as datas. Você sabe a data que você chega e a data que você vai embora. B: O tempo é contado assim: E aí, tá há quanto tempo aí? Ou, então: Que dia você vai embora? F: Faltam tantos dias. B: É. Falta uma semana.

As distorções de tempo objetivo versus subjetivo estão ligadas às frequentes queixas em torno do, assim chamado, relógio biológico: - "A gente tem trabalho noturno lá. Isso também é um estresse, porque você acaba causando um distúrbio no seu relógio biológico." A periculosidade inerente às condições offshore, entretanto, também configuram outro tempo, que não é descrito como marcado pelo relógio... mas por uma bomba relógio:

- Eu sei que tô numa bomba relógio [...] Eu não vou dizer que não é estressante, lá pro décimo dia, eu tô querendo a minha casa, sabe? Mas pô... Mais quatro diazinhos, tô em casa.

No processo de trabalho Taylorista/Fordista, o tempo era visto de forma objetiva, enquadrado dentro de uma linha de montagem. Os operários de então o experimentavam em termos de um mito do eterno retorno, objetivado em uma monotonia cotidiana que sempre se repetia. A exploração de petróleo offshore, entretanto, se alinha ao novo paradigma do mundo do trabalho, consequência da reestruturação produtiva em bases flexíveis, e circunscreve o petroleiro em um tempo calcado na rotatividade, na intensificação da velocidade da produção (GRISCI, 1999). Por isso, o tempo assimétrico é interpretado como algo fora de um eixo estável: - "Com essas viradas [de horários] que tem, a pessoa não consegue dormir"; mas também percebido segundo uma intensidade avassaladora:

- É, com o tempo as pessoas vão se adaptando, mas a questão, a questão por si só, é aquela única, você passou trilhões de dias embarcado. Você ainda tem psicologia, você ainda tem mente? Será?

\subsection{A pesquisa indicou que os trabalhadores tendem a conceber a própria vida de forma dissociada}

Conforme foi constatado, então, o tempo, enquanto percebido no ambiente offshore, não é um dado naturalizável. Não se trata de ver horas, marcar cronogramas, e consultar calendários. A própria noção do tempo fica alterada, se o trabalhador está dentro ou fora da plataforma:

- É cruel pegar na rotina! Você tem toda sua vida normal em terra e de repente chega o dia do embarque... tem a quebra... de acordar às 6 h da manhã e trabalhar!

Longe de configurar uma previsível cronologia de ações, o tempo sofre uma dissociação. O que há são tempos interpretados de modo muito divergente.

Contudo, a percepção de uma assimetria entre os tempos de trabalho-embarcado/descansodesembarcado, apresentada no tópico anterior, leva a consequências ainda mais graves. Principalmente porque não é só a cadência da vida que fica alterada, mas até a própria vida em si. De fato, um padrão identificado nas respostas dadas pelos grupos diz respeito à dada percepção que o trabalhador embarcado em plataformas marítimas desenvolve em relação à própria vida. Como a discussão do grupo foi conduzida várias vezes com tipos parecidos de participantes, para 
se identificar características e posturas, verificou-se que os trabalhadores offshore tendem a conceber - não só a marcação do tempo, mas mais do que isso - a própria vida de forma dissociada, dividida, partida: "Você tem uma vida dupla, cara."

Inegavelmente, tal alusão à vivência cindida ocasionada pelos "dois mundos", o mundo da plataforma e o mundo da terra firme, é bastante frequente (vide também estudos sobre mergulhadores offshore em Figueiredo e Athayde (2005)). Nos grupos focais emergiram muitas declarações nessa direção - "No caso, você tem duas vidas. Você é uma pessoa lá e outra pessoa aqui" - porque assinalavam claramente a percepção da própria existência em termos de uma cisão

- Bom, pra tentar esquecer essa parte negativa aí, você desliga um pouco lá de cima, das coisas que aconteceram lá em cima. É tentar esquecer. Entrou dentro de casa... é outro mundo aqui. Lá em cima é um mundo, e aqui embaixo é outro.

Muitos problemas surgem pela dificuldade de harmonizar essas, assim chamadas, duas vidas -

O trabalho embarcado acabou com meu casamento. Nos primeiros três dias de desembarque não tem aquele diálogo dentro de casa, porque eles falam de uma coisa e eu quero falar de outra. Eu ainda tô muitas vezes com o serviço na cabeça, então nesses primeiros três dias não há diálogo dentro de casa porque não houve ainda aquele entrosamento. Às vezes leva três ou quatro dias pra haver aquele entrosamento dentro de casa, pra eu me habituar à nova vida aqui em terra. E é a mesma coisa quando eu chego lá, os três primeiros dias são terríveis, até eu me habituar àquela rotina de lá, o clima é totalmente diferente.

Da mesma forma, a dimensão relacional se estabelece em torno de eixos distintos

- Praticamente você fica meio ano lá em cima e meio ano aqui embaixo, então você tem praticamente uma família lá em cima e aqui embaixo você também tem outra. Praticamente isso, são duas famílias.

O trabalhador offshore, portanto, fica diante de uma nova maneira de viver - sobreviver? - tão dissociada que o leva a colocar sua vida emocional à deriva. $\mathrm{O}$ que resulta em um quadro de ansiedade e sofrimento psíquico pela impossibilidade de organizar e autogerir a própria vida:

- O pessoal tem tique, tem uma parada estranha. Aí, quem tem mais de dez anos [embarcado] começa a tomar remedinho. Começa tomando a metade de um comprimido, depois toma o remédio todo.
Esse profundo descompasso existencial foi muitas vezes referido nos grupos focais: "Pra gente não faz diferença se é feriado, ou se não é. Todo dia é igual. Todo dia é segunda-feira." A ideia, então, é que há uma vida composta de dias iguais (iguais e ruins, vide a referência irônica à segunda-feira) que se opõe à outra vida, mais dinâmica, com dias novos e diferentes. Dissonância que traz em seu bojo o desgaste mental:

A: Eu acho que chega um ponto que se você não estiver bem, tem uma fase que você dá uma pirada. Eu dei, e não foi legal. B: Porque você está lá embarcado, e estão acontecendo coisas em terra que você não pode resolver. Então, com isso, você fica frustrado. A: Eu dei uma surtada lá. Pirei, pirei mesmo. Aî juntou tudo, foi problema de terra, problema de bordo, juntou tudo. E você não aguenta.

Os episódios que se referem à saúde mental no ambiente de trabalho são recorrentes:

Tem vários! Por exemplo, tem um cara que fica com uns tiques. Ele senta na cadeira e fica balançando, você fala com ele e ele nem está aí para você. Ele está desligado do mundo. Outro fala sozinho. O outro quando você passa por ele, ele bate continência do nada.

Por causa de questões vinculadas ao sofrimento psíquico, há ocasiões, inclusive, em que o trabalhador é deslocado para outra plataforma:

Tem uma pessoa na plataforma vizinha que trabalhou um tempo em terra, porque o cara surtou. Chegou o dia de embarcar, e ele disse que não ia embarcar! Teve que fazer um tratamento. $\mathrm{E}$ como ele dizia que o problema era a plataforma, estão mandando ele para a nossa!

Realmente, essa dinâmica de vida, que se alterna dentro e fora da plataforma, é interpretada pelos trabalhadores como indevida, como característica de uma atividade que não é normal

- Você tem os dias ruins que você passa lá em cima. Só que em contrapartida tem os dias que fico aqui, que são dias de folga. Depois fica difícil se acostumar, às vezes, num trabalho normal.

Os trabalhadores offshore se sentem deslocados, tanto sincronicamente, em dado ambiente e situação de folga ou trabalho, quanto diacronicamente, pois perdem a noção de uma vida que se direciona rumo a um objetivo. Eles percebem que, por trabalharem em plataformas marítimas, o planejamento da vida pessoal às vezes se torna impossível, pois tudo assume um ritmo imprevisível 
- Lá em cima é um estresse mental também, porque é tensão pra todo lado. E a quantidade de dias que você fica lá em cima, quando você desce, voa aqui embaixo, nesses dias de folga. Essa folga tem que ser, tinha que ser maior.

A folga, todavia, longe de ser solução, também faz parte do problema, pois essa dissociação envolve também aspectos mínimos do cotidiano. Os trabalhadores agem como se houvesse duas vidas, duas formas de lidar com as interações sociais. Uma dentro e outra fora da plataforma. Essa percepção é relatada mesmo em face de aspectos extremamente corriqueiros

- Aí você desce, né? Muda o horário de dormir, de comer. Lá são de três em três horas, aí, às vezes em casa, você chega, já tá fuçando e não tá no horário.

O trabalhador offshore entende a folga em termos de uma ruptura vivencial que ocorre quando ele desce da plataforma. Em casa, a vida é vista de forma diferenciada, mas ele tende a não se adaptar

- Uma das coisas que me afetam até hoje, no meu caso, é a alimentação. Eu sento na mesa, e não espero mais ninguém, vapo, vapo, comi e levanto. É a habituação ao horário de lá, do trabalho de lá, né? Pois, lá muitas vezes você não tem hora de almoço e, às vezes, acontece de você estar comendo e ter de largar a comida e sair pra atender. Então, o que é que veio? Trouxe isso pra dentro de casa, e muitas vezes isso gera um atrito pra dentro de casa.

As distintas vidas se chocam, causam atritos dentro de casa, mas também fora, na rua

- O ritmo de vida ficou um pouco mais acelerado. É tudo pra ontem. Por exemplo, quando você está em terra e tem que encarar uma fila de banco, você não tem paciência, você quer resolver na hora. Você vai num restaurante e você quer ser atendido, pra ontem. Então, você se habitua a aquele ritmo de resolver tudo rápido, rápido, de resolver tudo rápido. Porque você sempre é cobrado pra fazer as coisas bem feitas e rápido. E eu acho que você se habitua a isso.

\subsection{A pesquisa indicou que os trabalhadores off ore tendem a conceber os ganhos de forma ambígua}

Diante dos problemas psicológicos ressaltados até aqui, uma questão se mostrou muito importante na pesquisa. Pois se há tantas dificuldades, o que o petroleiro assume como positivo? Tal indagação implicou uma análise mais detida daquilo que eles consideravam como ganhos. O levantamento das respostas, porém, indica novas ambiguidades.

No momento em que, no grupo focal, surge a pergunta - "Na opinião de vocês, o que vocês ganham e o que perdem trabalhando na plataforma?" - é possível vislumbrar certa similaridade entre as respostas porque elas geralmente apontam a remuneração em si como algo com a qual, ao mesmo tempo, ganham e perdem.

A caracterização, por exemplo, do ambiente de trabalho em uma plataforma marítima como um presídio, feita dentro de um grupo, evidencia o quanto o paradoxo está presente. Há a desvantagem de se estar em um ambiente de confinamento, mas a vantagem de se receber salário. Mas será que vale a pena? Nesse caso, em que se transforma o trabalhador? - "É um presidiário remunerado, né?" - afirmou um dos componentes.

O imperativo aludido por outro trabalhador - "Existe um mercado aí fora e se eu não fizer, tem quem faça." - retrata o quanto essa situação de trabalho precisa ser concebida segundo a ordem política e econômica, determinada pelo nível estabelecido na correlação de forças sociais que se enfrentam no modo de produção capitalista. Muitos trabalhadores offshore compartilham a opinião de que fora das atividades em plataformas marítimas não seriam bem remunerados. Inegavelmente, os incentivos pessoais, em termos de melhores salários e benefícios decorrentes, procuram amenizar as contradições na base da produção (CARNOY, 1990). Contudo, o que se verifica é que a ambiguidade permanece

- No meu caso, ganho um pouco de dinheiro a mais, mas perco $50 \%$ da minha vida. É uma vida morta lá. Só resumida ao trabalho e ao dormir, então você perde nesses quinze dias de trabalho metade da sua vida. Então, metade da sua vida fica lá, presa.

Como o grupo focal suscita um diálogo marcado pelo estímulo aos debates abertos, diante da opinião de que o trabalho offshore implica perda de metade da vida, outro participante desse mesmo grupo discordou
- Agora, eu não diria que você perde 50\% da sua vida. Não, você perde $100 \%$. Porque muitas vezes você está aqui em terra e tem que ir para embarcar. Às vezes você é chamado para embarcar a qualquer momento. Então, você se acostuma. Você passa a viver todos os dias como se fossem o último, o último de folga.

Estabelecer para si a condição de viver todos os dias como se fosse o último de folga é o mesmo que dizer que no trabalho não há vida. Algo que, aliás, foi constatado por outro trabalhador - "Você não tem direito de viver enquanto você está embarcado." - e as razões para a defesa dessa opinião são muitas: 
- Você não tem direito ao seu aniversário. Se cair na sua escala... você tá lá dentro. No meu caso, os meus netos nasceram e eu tava embarcado. Você é cortado de todos os direitos durante este período.

A percepção do trabalhador é a do ganho como uma perda

- O que eu ganho, bom, o que eu ganho no papel mesmo é isso daí, o meu salário, o meu ganha pão. O que eu perco é minha juventude, você fica velho mais rápido, você se estressa.

Ou, ainda, concebe-se o ganho como paradoxal, reversível

- E tem o outro lado que você ganha um pouco mais de dinheiro. Ganha um pouco mais de dinheiro, mas esse dinheiro muitas vezes é revertido aqui embaixo. Você gasta mais com a saúde do que gastaria se normalmente trabalhasse aqui em terra.

O salário, em si, é referido muitas vezes

- A parte financeira nem sempre compensa muito. Às vezes as pessoas aqui embaixo pensam que é muito grande, mas não é tão grande assim.

As implicações dessa ambiguidade em relação aos processos de ganho/perda são muito grandes no campo da saúde mental do trabalhador. Particularmente no que diz respeito a esse padrão identificado entre os trabalhadores, em que os ganhos são vistos como perdas, de modo "revertido". Ora, é indiscutível que a atividade offshore constitui fator de crescimento econômico, emancipação financeira e prosperidade, tanto para os trabalhadores das plataformas marítimas, quanto para as cidades do norte fluminense beneficiadas pelos royalties do petróleo. No entanto, o que se destaca nos dados colhidos dentre os grupos focais é que esse ganho, não é só ganho. É também perda, no âmbito do sofrimento psíquico e da subjetividade.

Assim, o trabalho altamente qualificado desenvolvido nas plataformas pode ser efetivamente compreendido como possibilidade de satisfação de algumas necessidades fundamentais. Todavia, por outro lado, igualmente pode contraditoriamente representar fontes de reforço dos sentimentos de impotência, de desvalorização e de não reconhecimento do sujeito enquanto pessoa e ator social (SANTOS; SANTOS, 1993). Tal temática, portanto, precisa ser problematizada em termos suficientemente abrangentes, que englobem os vínculos entre o desgaste mental e a questão da atividade do trabalhador.

\section{Considerações finais}

A perspectiva da Psicologia do Trabalho aqui adotada parte da premissa de que a saúde mental no trabalho está indelevelmente ligada aos processos históricos e sociais. Dessa forma, este artigo procurou mostrar que, se o final dos anos 1970 pode ser considerado o momento a partir do qual a Petrobras investiu em pesquisa para desenvolver inovação tecnológica na área de prospecção e perfuração em alto mar, o momento em que os resultados se tornaram mais efetivos foi somente a partir da segunda metade da década de 1980, ocasião em que a empresa fez descobertas importantes em águas profundas e ultraprofundas, nos campos petrolíferos de Albacora, Marlim, Marlim Sul, Marlim Leste, Barracuda, Caratinga, Espadarte e Roncador.

Ao longo desses anos, a face mais enfatizada dos problemas foi a extrema periculosidade do trabalho em plataformas marítimas. Depois dos acidentes com a Plataforma Central de Enchova PCE-1 (na década de 1980) e, principalmente, com a P-36, em 2001, a sociedade brasileira tomou conhecimento das condições mais visíveis do trabalho offshore. No entanto, no que diz respeito ao desgaste mental e ao sofrimento psíquico imbricados nessas atividades, nem sempre a percepção tem sido tão clara. Se por um lado os acidentes de grandes proporções e os episódios de danos ambientais não passam despercebidos, a dimensão da saúde mental do petroleiro nem sempre é vislumbrada.

Dessa forma, este artigo teve como objetivo lançar luz sobre esses aspectos, ao investigar os processos psicológicos de petroleiros offshore no âmbito do trabalho embarcado realizado em plataformas marítimas. E, consequentemente, para alcançar tal propósito, utilizou como perspectiva metodológica entrevistas realizadas em grupos focais, principalmente porque o dialogismo bakhtiniano implicado na interpretação dos dados permitiu enfatizar elementos que ainda não tinham sido adequadamente ressaltados, conforme levantamento bibliográfico apresentado.

Inegavelmente, o trabalho com os grupos focais permitiu verificar que o confinamento, a separação da família e o isolamento social são comumente referidos pelos trabalhadores como circunstâncias negativas. $\mathrm{O}$ que também pode ser dito dos relatos de quadros psicológicos associados ao estresse, depressão e ansiedade; transtornos que já tinham sido assinalados por outros autores. Porém, nesta discussão suscitada com os grupos focais, foram constatados alguns outros aspectos que aqui receberam um relevo especial.

De fato, uma das coisas que a pesquisa indicou é que os trabalhadores offshore tendem a conceber o tempo e a própria vida de forma assimétrica e dissociada. Conforme foi visto nos depoimentos colhidos no grupo focal, a saúde mental do trabalhador embarcado em plataformas marítimas é grandemente afetada pela cisão existencial que ele experimenta ao perceber a 
fragmentação de sua vida em vivências mutuamente excludentes - dentro e fora da plataforma.

Além disso, o trabalho com os grupos focais igualmente apontou que os trabalhadores offshore tendem a conceber os ganhos de forma ambígua. $\mathrm{O}$ que ele ganha, em certo sentido é também o que ele perde. E a extensão de tal ambiguidade leva a uma diminuição do limite que separa, dentro do trabalhador, o sentimento de realização e a sensação de perda. Fato que causa grande angústia e consiste em mais um fator de sofrimento psíquico.

Esta análise, portanto, permite o desvelamento de modos de subjetivação do trabalhador offshore, particularmente ligados aos processos de saúde/ doença, que se constituem em decorrência de um complexo quadro, pela integração de elementos tanto da macroestrutura social (do desenvolvimento econômico da indústria offshore na Bacia de Campos), quanto da percepção que o trabalhador tem de si mesmo e de sua atividade produtiva.

\section{Referências}

ALVAREZ, D. et al. Reestruturação produtiva, terceirização e relações de trabalho na indústria petrolífera offshore da Bacia de Campos (RJ). Gestão \& Produção, v. 14, n. 1, p. 55-68, 2007. http://dx.doi.org/10.1590/ S0104-530X2007000100006

BAKHTIN, M. Marxismo e Filosofia da linguagem. 11. ed. São Paulo: Hucitec. 2004.

BRASIL. Lei 5.811, de 11 de outubro de 1972. Dispõe sobre o regime de trabalho dos empregados nas atividades de exploração, perfuração, produção e refinação de petróleo, industrialização do xisto, indústria petroquímica e transporte de petróleo e seus derivados por meio de dutos. Diário Oficial da República Federativa do Brasil, Brasília, DF, out. 1972. Disponível em: <http:// www.jusbrasil.com.br/legislacao/111146/lei-5811-72>. Acesso em: 18 mar. 2013.

BRUNI, P. B. Petrobras: Estratégia e esforço tecnológico para alavancar competitividade. Petróleo e Gás Brasil, v. 3, n. 3, p. 4-6, 2002.

CARLINI-COTRIM, B. Potencialidades da técnica qualitativa grupo focal em investigações sobre abuso de substâncias. Revista de Saúde Pública, v. 30, n. 3, p. 285-293, 1996. http://dx.doi.org/10.1590/ S0034-89101996000300013

CARNEIRO, J. C. O trabalho off-shore e o seu comprometimento na saúde do trabalhador. 2006. Trabalho de Conclusão de Curso (Graduação em Psicologia)-Universidade Estácio de Sá, Campos dos Goytacazes, 2006.

CARNOY, M. Educação, economia e estado: base e superestrutura: relações e mediações. 3. ed. São Paulo: Cortez, Autores Associados, 1990.

CASTRO, A. C. Atividades laborais em plataformas marítimas no Brasil: A Gestão do Conhecimento na perspectiva da Psicologia do Trabalho. Cuadernos de Psicologia, v. 14, p. 55-65, 2012.
CASTRO, A. C. et al. Psicologia do Trabalho e Subjetividade do Trabalhador Offshore. In: SIMPÓSIO DE ENGENHARIA DE PRODUÇÃO SIMPEP, 14., 2007, Bauru. Anais... Bauru, 2007.

CASTRO, A. C.; IGNÁCIO, A. G.; PINTO, V. N. Com Sartre na Petrobrás: Fragmentos existenciais do petroleiro off-shore. In: CONGRESSO BRASILEIRO DE PSICOTERAPIA EXISTENCIAL, 8., 2006, São Paulo. Anais... São Paulo, 2006.

CASTRO, A. C.; NUNES, D. K. P. Ações e relações entre Gestão do Conhecimento e estresse do petroleiro offshore. In: CONGRESSO NACIONAL DE EXCELÊNCIA EM GESTÃO - CNEG, 4., 2008, Niterói. Anais... Niterói, 2008a.

CASTRO, A. C.; NUNES, D. K. P. Análise crítica do Gerenciamento de Stress em plataformas marítimas. In: ENCONTRO NACIONAL DE ENGENHARIA DE PRODUÇÃO - ENEGEP, 28., 2008, Rio de Janeiro. Anais... Rio de Janeiro, 2008b.

CASTRO, A. C.; PINTO, V. N.; IGNÁCIO, A. G. A Organização do Trabalho e suas Implicações na Saúde Mental do Trabalhador. In: ENCONTRO NACIONAL DA ASSOCIAÇÃO BRASILEIRA DE PSICOLOGIA SOCIAL, 13., 2005, Belo Horizonte. Anais... Belo Horizonte, 2005.

CASTRO, A. C.; PORTUGAL, F. T.; JACO-VILELA, A. M. Proposição bakhtiniana para análise da produção em psicologia. Psicologia em Estudo, v. 16, n. 1, p. 91-99, 2011. http://dx.doi.org/10.1590/ S1413-73722011000100011

CASTRO, A. C.; VINAGRE, R. F. A percepção do tempo subjetivo e o estresse no trabalho offshore. In: ENCONTRO NACIONAL DE ENGENHARIA DE PRODUÇÃO - ENEGEP, 29., 2009, Salvador. Anais... Salvador, 2009.

FIGUEIREDO, M. G.; ATHAYDE, M. R. C. Organização do trabalho, subjetividade e confiabilidade na atividade de mergulho profundo. Produção, v. 15, n. 2, p. 172-183, 2005. http://dx.doi.org/10.1590/ S0103-65132005000200004

FREITAS, A. G. Processo de aprendizado tecnológico na periferia: o caso da Petrobrás. Revista Brasileira de Energia, v. 4, n. 2, p. 71-99, 1995.

FREITAS, C. M.; SOUZA, C. A. V.; MACHADO, J. M. H. Acidentes de trabalho em plataformas de petróleo da Bacia de Campos. Cadernos de Saúde Pública, v. 17, n. 1, p. 117-130, 2001.

FURTADO, A. T.; FREITAS, A. G. Nacionalismo e aprendizagem no programa de Águas profundas da Petrobras. Revista Brasileira de Inovação, v. 3, n. 1, p. 55-86, 2004.

GARDELL, B. Work Participation and Autonomy: A Multilevel Approach to Democracy at the Workplace. In: JOHNSON, J. V. The psychosocial work environment: Work organization, democratization, and health. New York: Baywood Publishing, 1991.

GONDIM, S. M. G. Grupos focais como técnica de investigação qualitativa: desafios metodológicos. Paideia (Ribeirão Preto), v. 12, n. 24, p. 149-161, 2002.

GRISCI, C. L. I. Trabalho, tempo e subjetividade: Impactos da Reestruturação Produtiva e o Papel da Psicologia 
nas Organizações. Psicologia - Ciência e Profissão, p. 2-13, 1999.

KIND, L. Notas para o trabalho com a técnica de grupos focais. Psicologia em Revista, v. 10, n. 15, p. 124-136, 2004.

KRUEGER, R. A Focus Groups. A pratical guide for applied research. 2. ed. Thousand Oaks: Sage Publications, 1994.

LUCCHESI, C. F. Petróleo. Estudos Avançados, v. 12, n. 33, p. 17-40, 1998. http://dx.doi.org/10.1590/ S0103-40141998000200003

MILANI, E. J. et al. Petróleo na margem continental brasileira: geologia, exploração, resultados e perspectivas. Revista Brasileira de Geofísica, v. 18, n. 3, p. 351-395, 2000. http://dx.doi.org/10.1590/ S0102-261X2000000300012

MOITAS, D. Plataformas petrolíferas oferecem salários de até R\$ 9 mil. Jornal Extra, p. 8, 23 jul. 2011.

ORTIZ NETO, J. B.; COSTA, A. J. D. A Petrobrás e a exploração de petróleo offshore no Brasil: um approach evolucionário. Revista Brasileira de Economia, v. 61 , n. 1, p. 95-109, 2007. http://dx.doi.org/10.1590/ S0034-71402007000100006

ORTIZ NETO, J. B.; SHIMA, W. T. Trajetórias tecnológicas no segmento offshore: ambiente e oportunidades. Revista de Economia Contemporânea, v. 12, n. 2, p. 301-332, 2008. http://dx.doi.org/10.1590/ S1415-98482008000200005

PENA, A. C. Relato de pesquisa: a influência do contexto ambiental nos trabalhadores off-shore de uma plataforma petrolífera. Psicologia, Ciência e Profissão, Brasília, v. 22, n. 1, p. 112-119, 2002. http://dx.doi.org/10.1590/ S1414-98932002000100012

RODRIGUES, V. F. Relações de trabalho em unidades de perfuração marítima: Estudo de caso com ênfase em trabalho em turnos. 2001. Dissertação (Mestrado em Administração)-Universidade José do Rosário Vellano, Alfenas, 2001.

SAMPAIO, J. J. C. Saúde mental e trabalho petroleiro: gente em desconforto, mal estar e sofrimento In:
VENÂNCIO, A. T. A.; CAVALCANTI, M. T. (Org.) Saúde mental - Campo, Saberes e Discursos. Rio de Janeiro: Edições IPUB, 2001.

SANTOS, M. F.; SANTOS, E. A. Identidade e Trabalho: Um estudo de caso. Estudos de Psicologia, v. 10, n. 3, p. 57-72, 1993.

SCHELLER, F. Trabalho em plataforma de petróleo não é para todo mundo: Mesmo com salários mais altos, há dificuldade de retenção de trabalhadores no segmento off shore. O Estado de S. Paulo, São Paulo, p. 16, 11 jan. 2012.

SILVA JÚNIOR, D. I.; FERREIRA, M. C. Escala para avaliação de estressores ambientais no contexto off-shore oil (EACOS). Avaliação Psicológica, v. 6, n. 2, p. 139-146, 2007.

SINDICATO DOS PETROLEIROS DO NORTE FLUMINENSE - SINDIPETRO-NF. Dossiê do Sindicato dos Petroleiros do Norte Fluminense para a Comissão Parlamentar de inquérito que apura "Falta de Segurança e Condições de Trabalho nas Plataformas Petrolíferas do Estado do Rio de Janeiro". Macaé: Assembleia Legislativa do Estado do Rio de Janeiro, 1997. Resolução 509/97 da Assembleia Legislativa do Estado do Rio de Janeiro, 6 jun. 1997.

TEIXEIRA, C. Maria. As mulheres no mundo do trabalho. Psicologia: Teoria e Pesquisa, v. 25, n. 2, p. 237-244, 2009.

THIELMANN, B. Falta de engenheiros faz com que profissão esteja em alta no Brasil: Um engenheiro recémformado pode ganhar até $\mathrm{R} \$ 5$ mil mais benefícios. Jornal Hoje, 11 mar. 2013. Disponível em: <http://g1.globo. com/jornal-hoje/noticia/2013/03/falta-de-engenheiros -faz-com-que-profissao-esteja-em-alta-no-brasil.html>. Acesso em: 15 mar. 2013.

VIDEIRA, E. M. Os processos identitários do trabalhador petroleiro na década de 90: Uma análise psicossocial. 2001. Dissertação (Mestrado em Psicologia)-Universidade de São Marcos, São Paulo, 2001. 